\title{
LA HISTORIA HACIA EL TERCER MILENIO
}

\section{Josep Fontana}

El historiador refleja el tiempo en que vive, aunque no siempre se dé cuenta de ello. La crisis de la ciencia histórica de nuestro tiempo es un reflejo de otra crisis más profunda: la de las expectativas de futuro que basábamos en una concepción de la historia que parecía permitirnos hacer previsiones sobre el futuro. Estas expectativas nacieron de un modelo interpretativo que surgió con la visión de la historia elaborada por la ilustración escocesa en el siglo XVIII, con su teoría de los "cuatro estadios", que situaba las distintas sociedades conocidas en un esquema único y ordenado de desarrollo, cuyas etapas habían de recorrer sucesivamente todos los pueblos.

Esta concepción lineal del progreso estaba en la base de las más diversas escuelas históricas posteriores, reforzada por una visión determinista de la ciencia que partía de Newton y de Laplace, y por la transposición de ese mecan icismo al terreno humano, que asignaba a la historia el objetivo de llegar a un conocimiento perfecto del mundo social, como lo sostenía el anarquista francés Charles Malato, que quería una ciencia histórica capaz de "deducir con precisión matemática las causas de los movimientos profundos que agitan las moléculas humanas" ${ }^{\prime \prime}$.

Este esquema fue el que nos llevó a predecir que la consecuencia segura del progreso histórico sería la de que en un futuro tal vez no muy lejano se podría conseguir que el crecimiento económico se generalizase al mundo atrasado y que las sociedades desarrolladas consiguieran la eliminación de la pobreza. Cosas que parecían al alcance de la mano durante la larga y excepcional etapa de prosperidad que se vivió después de la Segunda guerra mundial. 
Esta perspectiva fue la que inspiró el llamado 'punto cuarto' del discurso sobre el estado de la Unión del presidente Truman, de 20 de enero de $1949^{2}$. Junto al apoyo a las Naciones Unidas, al Plan Marshall y a la creación de la OTAN, Truman propuso a los norteamericanos embarcarse "en un nuevo y vigoroso programa para hacer accesibles los beneficios de nuestros avances científicos y nuestro progreso industrial para la mejora y crecimiento de las áreas subdesarrolladas". El objetivo era "ayudar a los pueblos libres del mundo, a través de sus propios esfuerzos, a producir más alimentos, más vestidos, más materiales de construcción y más fuerza mecánica para aligerar sus cargas" . Este discurso, el primero en que se interpretó el problema de la pobreza en términos de 'subdesarrollo', inauguró un periodo de cerca de cincuenta años de mesianismo desarrollista: lo que Rist llama la doble utopia del 'estado del bienestar' para los países del norte y de los programas de desarrollo para los países del sur.

Pero el crecimiento económico de posguerra duró poco más de dos décadas y, pasadas éstas, se pudo ver que no se trataba de una aceleración permanente del curso de la historia, sino tan solo de una etapa pasajera y posiblemente irrepetible, por lo menos a medio plazo. Las tasas de crecimiento del Producto Interior Bruto per cápita de los países desarrollados, que habían alcanzado máximos históricos en el periodo que va de 1950 a 1973, se redujeron en el de 1973 a 1992 a cifras semejantes a las de los años anteriores a la primera guerra mundial (a las de 1870 a 1913), al tiempo que se agudizaban en ellos el paro y la pobreza y que el 'estado de bienestar' comenzaba a entrar en crisis, iniciando un proceso de desguace que sigue en la actualidad. Peor ha sido el caso de los países atrasados. No solo no han visto cumplirse las promesas de crecimiento, sino que en las ultimas décadas ha ido aumentando la distancia que les separaba de los ricos, lo cual ha sucedido al propio tiempo en que han ido quedando marginados de los tráficos internacionales (desde los años ochenta la participación de África en el comercio mundial ha caído de un 4 a cerca de un 2 por ciento).

Un informe de las Naciones Unidas revela que de 1960 a 1993 la diferencia entre la renta per cápita de los países industrializados y la de los países pobres se ha triplicado. Lo más grave es, además, que este empobrecimiento no es tan solo relativo, sino que en muchos casos tiene también un carácter absoluto: en setenta países distintos los ingresos medios son hoy inferiores a los de hace treinta años.

Fracasaron la mayor parte de los países que habían intentado repetir los modelos industrializadores avanzados, y que acabaron descubriendo que la receta no daba los mismos resultados en contextos y momentos diferentes. Pero

2. Gilbert Rist, The history of development. From western origins to global faith, Londres, Zed Books, 1997. 
no salieron mejor parados los que probaron vías alterativas. El hundimiento -primero económico y político después- de los países europeos del llamado "socialismo real" arruinó las esperanzas que muchos habían depositado en este modelo de industrialización forzada, y tampoco las terceras vías dieron resultado: tras la experiencia del Ilamado 'socialismo africano', que quiso buscar una vía propia de crecimiento, alejada de los dos modelos dominantes, Tanzania tiene en la actualidad un Indice de Desarrollo Humano de $0^{\prime} 357$, por debajo de los de Nigeria o Bangladesh.

Una de las causas de este empobrecimiento es el endeudamiento a que les condena el pago de las deudas que contrajeron con la esperanza de financiar su desarrollo: de 1982 a 1990 los países deudores pagaron cerca de un billón y medio de dólares a sus acreedores, con el resultado de que en 1990 sus deudas globales habían aumentado en un $61 \%$ respecto de las cifras de 1982 . Esta situación ha obligado a muchos a aceptar los programas de ajuste estructural propuestos por el Banco Mundial y el Fondo Monetario Internacional, que han traído aparejado normalmente un aumento de su dependencia y de la pobreza del conjunto de la población, al potenciar la producción para la exportación a expensas de la de alimentos para el propio consumo.

El fallo de las viejas profecías ha llevado a reemplazarlas por nuevas previsiones. Del 'desarrollismo' hemos pasado a la globalización o mundialización, de la vieja religión a otra nueva, con dogmas irracionales como el de la 'competitividad' ${ }^{\prime 3}$ y con un nuevo código moral que incluye la santificación de la libre iniciativa y el retorno a la lucha por la supervivencia, en condiciones en que nada garantiza que vaya a triunfar el más apto.

Era lógico que el fracaso de las profecías fundadas en la visión lineal del progreso obligase a revisar las reglas de la evolución de las sociedades humanas en que ésta se asentaba. La decadencia de las corrientes de pensamiento histórico que dominaron en las décadas que siguieron al fin de la Segunda Guerra Mundial se estaba anunciando desde los años setenta, pero se aceleró con la crisis de 1989: un año que vio, a la vez, el inicio del hundimiento de los regímenes del este europeo, la contraofensiva conservadora en torno al segundo centenario de la Revolución francesa y la aparición del artículo de Fukuyama que proclamaba que el tiempo de las revoluciones y contrarrevoluciones había terminado porque, sencillamente, habíamos llegado al fin de la historia.

¿Qué habían de hacer los historiadores, cuando se les negaba la validez de los modelos globalizadores, de uno u otro signo, que habían utilizado hasta entonces? La mayoría optó por seguir los caminos abiertos por el postestructuralismo a partir de Foucault, Deleuze o Derrida y se lanzó a cultivar el tipo de historia postmoderna que rechaza las periodizaciones y las interpretaciones

3. Paul Krugman, El internacionalismo 'moderno'. La economía internacional y las mentiras de la competitividad, Barcelona, Crítica, 1997. 
globales, y que pide el reemplazo de la Historia, con mayúscula, por las historias, con minúscula, y el de las afirmaciones sobre la realidad por metáforas 4 .

No me parece, sin embargo, que la superación de la crisis del pensamiento histórico pueda venir de este tipo de propuestas, que se limitan a la negación global de lo anterior y su apresurada substitución por hallazgos puntuales que solo responden a una pequeña parte de nuestros problemas como historiadores, sino que exige un esfuerzo muy serio para recuperar, a la vez, unos fundamentos teóricos y metodológicos sólidos, y, sobre todo, el contacto con los problemas reales de los hombres y mujeres de nuestro tiempo, de los que las tendencias postmodernas nos han alejado.

La reconstrucción de los fundamentos de nuestro trabajo me parece que debería atender a tres grandes puntos en que nuestro instrumental ha fallado (tres puntos, por otra parte, estrechamente relacionados entre sí). En primer lugar, a la superación del modelo único de la evolución humana con sus concepciones mecanicistas sobre el progreso; en segundo lugar, a la búsqueda de una nueva forma de aproximación al estudio del acontecimiento - a la relación entre el hecho concreto y el contexto teórico en que lo situamos- $y$, finalmente, a un replanteamiento de las explicaciones habituales de los actos humanos, que han pecado por una sobrevaloración de su racionalidad. Analizar estos tres puntos me obligaría o a extenderme mucho o a ser demasiado esquemático, de modo que me limitaré ahora a considerar el primero de ellos.

A la propuesta de abandonar el esquema evolutivo único y el determinismo que lo animaba, nos debería estimular la consideración de lo que ha sucedido en el siglo XX con estas otras ciencias duras que tomábamos como modelo inalcanzable, deslumbrados por su supuesta capacidad de predecir, que se nos había enseñado que era el criterio fundamental para identificar la auténtica ciencia.

Porque sucede que mientras muchos historiadores estaban obsesionados con esta concepción mecanicista, la ciencia había abandonado las viejas ilusiones y había descubierto que el Universo era mucho más complejo que el reloj cósmico de Newton y de Laplace, y que el determinismo y la capacidad de predecir correspondían a un mundo de abstracciones, pero no al de la realidad. Para decirlo con las palabras del premio Nobel de química llya Prigogine: "Tanto en dinámica clásica como en física cuántica, las leyes fundamentales

4. Frederic Jameson, "Periodizing the 60s" en The ideolocfies of theory. Essays. II: Syntax of history, Minneapolis, University of Minnessota Press, 1988; Frank R. Ankersmit, History and topology. The rise and fall of metaphor, Berkeley, University of California Press, 1994, y "The origins of postmodernist historiography" en Jerzy Topolsky, ed., Historiography between modernism and postmodernism, Amsterdam y Atlanta, Rodopi, 1994, pp. 87-117; Keith Jenkins, ed., The ipostmodern history reader, Londres, Routledge, 1997; Mark Poster, Cultural history and postmodernity, New York, Columbia University Press, 1997. 
expresan hoy posibilidades y ya no certezas. No solo tenemos leyes, sino acontecimientos que no pueden deducirse de las leyes ${ }^{\prime \prime}$

Los cientificos naturales han abandonado hoy la vieja tentación del determinismo - de una explicación del mundo por unas pocas leyes fundamentalespara poner en un lugar central las relaciones no lineales, mucho más abundantes en la naturaleza, y sobre todo en la vida, que las que nos daban encadenamientos seguros de causas y efectos, y afirman que "la contingencia es la palabra clave de la ciencia actual en lo que se refiere a su concepción de las dinámicas temporales, superando así la vieja antinomia del azar y la necesidad" ${ }^{\prime \prime}$.

Se da hoy la paradoja de que, mientras muchos historiadores siguen buscando legitimaciones externas para su trabajo, son los científicos naturales los que han recuperado los valores de la historicidad y afirman, por ejemplo, que: "la naturaleza está constituida por acontecimientos y por las relaciones entre ellos, tanto como por substancias y particulas separadas. La historicidad es una característica importante de la ciencia" ${ }^{\prime \prime}$, de manera que un biólogo molecular nos asegura que su disciplina esta abandonando "la fútil búsqueda de leyes" y haciéndose cada vez más "histórica": "Muchos biólogos moleculares-concluye- están convirtiéndose en historiadores a su pesar" ${ }^{\prime \prime}$. ¿Por qué, pues, en lugar de seguirnos guiando por los modelos del pensamiento científico del siglo XIX no comenzamos también los historiadores a "convertirnos en más historiadores" como los biólogos moleculares y a inspirarnos en la ciencia de fines del siglo $X X$ ?

Los defectos del viejo modelo único de evolución social, basado en una concepción del progreso que consideraba la energía y la máquina como sus motores esenciales y que ve la industrialización como el punto culminante de la evolución humana, son tan evidentes que parece necesario que los reemplacemos con una reformulación profunda. Al proponer las formas de desarrollo económico y social actuales como el punto culminante del progreso -pese a sus deficiencias e irracionalidades- hemos seleccionado de entre todas las posibilidades abiertas a los hombres del pasado tan solo aquellas que conducían a este presente $y$ hemos menospreciado las alternativas que algunos propusieron.

El punto de partida de esta revision deberia ser el rechazo de la visión lineal de la historia que ha servido para justificar, a la vez, el imperialismo y las formas de desarrollo con distribución desigual, y el intento de construir, en su

5. I. Prigogine: La fin des certitudes, Paris, Odile Jacob, 1996, p. 14.

6. Jean-Marc Lóvy Leblond, "La science en son miroir", en Michel Cazenave, ed., Dictionnaire de l'ignorance, Paris, Albin Michel, 1998, cita de p. 24.

7. John Cornwell, en el prefacio de Nature's imagination, p. V.

8. Robert Pollack, Signs of life. The language and meaning of DNA, Nueva York, Houghton Mifflin, 1994, pp. 152-153. 
lugar, unas interpretaciones más realistas, capaces de mostrarnos no solo la evolución simultánea de lineas distintas, sino el hecho de que en cada una de ellas, incluyendo la que acabará siendo dominante, no hay un avance continuo en una dirección, sino una sucesión de rupturas, de bifurcaciones en que se pudo elegir entre diversas caminos posibles, y no siempre se eligió el que era mejor en términos del bienestar del mayor número posible de hombres y mujeres, sino que el que convenía -o por lo menos el que parecía convenir- a aquellos grupos que disponían de la capacidad de persuasión y de la fuerza represiva necesarias para decidir.

Hemos de elaborar una visión de la historia que nos ayude a entender que cada momento del pasado no contiene tan solo la semilla de un futuro predeterminado e inescapable, sino la de toda una diversidad de futuros posibles, uno de los cuales puede acabar convirtiéndose en dominante, por razones complejas, sin que esto signifique que es el mejor, ni, por otra parte, que los otros estén totalmente descartados.

Esta historia no lineal debería permitirnos recuperar muchas cosas que nos hemos dejado olvidadas por el camino de la mitología del progreso: el peso real de las aportaciones culturales de los pueblos no europeos, el papel de la mujer, la racionalidad de proyectos de futuro alternativos que no consiguieron imponerse, la importancia de la cultura de las capas populares... Y debería ayudarnos a escapar, con este enriquecimiento de nuestro horizonte, de la resignación a que pretende condenarnos el discurso actual de la mundialización.

Walter Benjamin Ilamó la atención hacia los males que producía esta visión lineal y los ilustró con el ejemplo del fascismo, que se tendía a ver como una aberración retrógrada o como algo excepcional, y por ello de supervivencia difícil, en lugar de entenderlo como un fruto lógico y natural de un tiempo y de unas circunstancias (como lo podemos ver hoy cuando renace sin producir demasiado escándalo). Y completaba el cuadro denunciando aquel otro error paralelo en que habían caído la izquierda y el movimiento obrero: el de creer que tenían las fuerzas de la historia de su parte, lo que acabaría dándoles la victoria. Y así están ahora los dos ${ }^{9}$.

Contra la historia que pretendía explicar las cosas 'tal como han pasado', - esto es, de la única manera en que podían pasar-Walter Benjamin proponía al historiador que trabajase como el físico en la desintegración del átomo, con el fin de liberar las enormes fuerzas que han quedado apresadas en la explicación lineal de la historia, que habría sido, según sus palabras "el narcótico más poderoso de nuestro siglo"10.

9. Aunque abundan las versiones castellanas de las "tesis" de Benjamin, se ha publicado recientemente una excelente compilación italiana que merece la pena utilizar: Walter Benjamin, Sul concetto di storia, a cura di Gianfranco Bonola e Michele Ranchetti, Turin, Einaudi, 1997.

10. Walter Benjamin, Paris, capitate du XIXe siécle. Le livre des passages, Paris, Editions du Cerf, 1989 , p. 480. 
Abandonadas en las bifurcaciones en que se hizo una elección -en las encrucijadas en que se escogió uno u otro camino-, o entre el bagaje de los que fueron derrotados, hay muchas cosas que merece la pena recuperar. No es lícito pensar, por poner un solo ejemplo, que el fracaso de los regímenes de la Europa oriental convierte en desdeñables las esperanzas y los esfuerzos de todos los hombres y mujeres que han luchado durante siglos para conseguir una sociedad más igualitaria. Su legado, que los regímenes políticos instaurados desde 1917 acabaron traicionando, forma parte, con otros muchos, de estas "enormes fuerzas" olvidadas en los rincones de una narración lineal del pasado: de una pretendida historia de progreso que, encima, termina mal.

Déjenme poner dos ejemplos de cómo el hecho de desembarazarnos de las visiones lineales de la historia nos puede ayudar a entender mejor algunos problemas del presente. El más evidente tal vez sea el que surge del abandono del mito de la "revolución industrial" como un proceso único, ejemplificado por el caso británico, que tendría como motor central el cambio tecnológico: la máquina de vapor y el telar mecánico.

No solo hemos cambiado nuestra visión de las etapas de este proceso, que no comienzan ahora por la oferta, esto es por los efectos de la tecnología, sino por la demanda, por la llamada "revolución del consumo", sino que, analizando ese punto central del mito en que aparece la fábrica como un paso decisivo en el progreso industrial, un economista radical norteamericano, Stephen Marglin, sugirió hace unos años que la fábrica no era un elemento necesario para el progreso de la producción, sino un instrumento de control de la fuerza de trabajo por parte del empresario.

Siguiendo por este camino, Sabel y Zeitlin mostraron hace unos años que había diversas vías de crecimiento industrial que no pasaban necesariamente por la fábrica. Estas ideas, expuestas inicialmente en un articulo de "Past and Present" las han desarrollado recientemente en un libro original y provocativo", en que reemplazan el viejo relato que contrapone un antiguo régimen de control gremial y producción manual artesana a una modernidad marcada por la libertad del mercado, la mecanización y la fábrica, por otro muy distinto. En la etapa final del antiguo régimen podríamos advertir, nos dicen, "la modernidad de la tradición", que estaba permitiendo mecanización y progreso tecnológico dentro del marco institucional vigente. A esta fase le sucedería, de mediados del siglo XIX a la primera guerra mundial, una nueva etapa de "batalla de los sistemas" , que vería la coexistencia de una industrialización de fábrica, con empresas integradas verticalmente que utilizaban sus costosos equipos para producir objetos estandardizados, y otra de unidades menores, capaces de cooperar entre si dentro de un marco de instituciones y de reglas que asegura-

11. Charles F. Sabel y Jonathan Zeitling, World of possibilities. Flexibility and mass production in western industrialization, Cambridge, Cambridge University Press, 1997. 
ban la colaboración, orientada hacia una especialización flexible (como la seda de Lyon, los cuchillos de Solingen, los relojes suizos...). La tercera etapa de este proceso, que puede fecharse de 1920 a 1970, habría sido la del triunfo de Ia producción de masa, pero la crisis de los años setenta del siglo XX, nos dicen, ha abierto una "nueva batalla de los sistemas", como consecuencia del estancamiento de los centros clásicos de producción de masa, bloqueados por su tradicionalismo.

El planteamiento de Sabel y Zeitlin -que rechaza como antihistórica la separación de lo tradicional y lo moderno, al igual que rechaza la de lo político y lo económico- tiene la virtud de reemplazar la vieja visión simplista que lo interpreta todo en función del progreso tecnológico, por otra completamente abierta, en que los hombres tienen la opción de seguir caminos distintos y toman decisiones, optando por uno o por otro de los diversos "futuros pos ibles". Por lo general, nos dicen, la opción de la producción fabril estandardizada se toma cuando una economía es estable, mientras que cuando el entorno es "volátil' resulta mucho mejor organizar cada escalón de la producción como una empresa independiente, colaborando en un marco en que unos arreglos institucionales adecuados garantizan la seguridad de los tratos, para realizar una producción flexible que hará posible sobrevivir a los cambios desfavorables del entorno.

Este análisis, tan distinto a los de Rostow o de Phyllis Deane, nos sirve para estudiar la crisis iniciada en los años setenta de nuestro siglo y nos ayuda a entender algunas de las paradojas de la recuperación económica de estos últimos años en los países desarrollados, en que el aumento de las cifras de producción industrial no ha ido acompañado, como en las fases de auge del pasado, por el de la productividad.

Un análisis de la situación actual en los Estados Unidos viene a concordar sorprendentemente con lo que nos dicen Sabel y Zeitlin, ya que llega a la conclusión de que nos encontramos ante una demanda que exige variedad, calidad y una renovación constante, y acaba con la siguiente previsión: "Se diría que la economía moderna puede estar volviendo a una versión en alta tecnología de una economía artesanal, basada en la habilidad del trabajador, las ideas y la capacidad inventiva, más que en el empuje de las grandes fábricas y las cadenas de distribución"12.

El segundo ejemplo es posiblemente más complejo, de modo que me limitaré a apuntarlo. Estamos todavía, y eso es sobre todo válido para la historiografía española, bajo la influencia del viejo mito que sostenía que las monarquías absolutas del Antiguo régimen pusieron las bases del estado moderno, lo que implicaba un paso adelante en el proceso de modernización.

12. Jeff Madrick, "Computers: waiting for the revolution", en New York Review of Books, 26 marzo 1998, pp. 29-33. 
Quienes sostienen esta mitología no parecen darse cuenta de que las monarquías absolutas entraron en crisis en todas partes y que el estado moderno, tal como lo conocemos, no surgió del modelo del absolutismo, sino, por el contrario, de los sistemas de gobierno limitado en que la monarquía se veía obligada a negociar con unas instituciones parlamentarias en que estaban representados los intereses dominantes de la sociedad. Este es el modelo que surgió en Inglaterra con la "glorious revolution" de 1688, el que se implantó en Francia desde 1789 y en España en la primera mitad del siglo XIX, después de que en todas partes se hubiera producido el fracaso del absolutismo. $Y$ este sería el modelo que adoptarían en el siglo XIX otros países, haciendo la revolución desde arriba, para evitar los riesgos de conflicto social en que podían incurrir si dejaban que el viejo aparato del absolutismo acabara de desgastarse.

Hoy sabemos que el progreso económico moderno solo podía producirse en aquellos países en que la existencia de instituciones representativas que controlaban la política económica daban garantías respecto del "trust", de la confianza en la estabilidad de las condiciones que eran necesarias para que se hicieran inversiones a largo plazo. Una confianza que faltaba allá donde el soberano podía cambiar unilateralmente las condiciones legales. Se ha demostrado qué esta garantía política de estabilidad ha sido necesaria para el desarrollo de los mercados $^{13}$, y que solo puede mantenerse cuando hay participación política de los grupos interesados. Como dice Powelson, el crecimiento económico moderno depende de que "los métodos, reglas e instrumentos de política e intercambio [sean] elaborados principalmente por negociación entre las partes a quienes conciernen: agricultores, terratenientes, productores y comerciantes ${ }^{\prime \prime 14}$. Y si de las consideraciones de carácter económico pasamos a las de la ciencia política, recuerden el predicamento actual de la visión de Putnam ${ }^{15}$ que sostiene que la viabilidad del estado representativo no está asegurada por el hecho de que se establezcan acuerdos desde arriba, sino que su fuerza depende de la solidez del tejido de la sociedad civil, que se asienta en el desarrollo de formas de asociación "horizontales" de los ciudadanos (gremios, sociedades de oficio, de ayuda mutua, culturales, etc.). Analizando las diferencias que existen entre el norte y el sur de Italia, Putnam nos dice que donde han dominado las relaciones verticales de jerarquía y deferencia, heredadas del absolutismo, el tejido de la sociedad civil es más débil y el asentamiento de las formas políticas representativas, cuando finalmente se ha producido, resulta difícil y precario.

13. Hilton L. Root, The fountain of privilege. Political foundations of markets in Old regime France and England, Berkeley, University of California Press, 1994.

14. John P. Powelson, Centuries of economic endeavor, Ann Arbor, University of Michigan Press, 1997, p. 1.

15. Robert Putnam, R. Leonardi y R. Y. Nanetti, Making democracy work: civic traditions in modern Italy, Princeton, Princeton University Press, 1993. 
Esta forma distinta de ver la génesis del estado moderno, que nos aparta de la vieja visión lineal, puede posiblemente servirnos para examinar con otros ojos los problemas actuales del estado que, tras haber llegado a su apogeo en las décadas de prosperidad que siguieron a la segunda guerra mundial, con el auge del llamado "estado de bienestar", entró en crisis a partir de 1975, con las dificultades económicas de los países industrializados, la incapacidad de los menos avanzados para hacer frente a las grandes deudas contraídas para financiar su crecimiento económico y el abandono del 'desarrollismo', y que ha conducido incluso al colapso de los aparatos del estado en algunos países, como ha sucedido en Afganistán, Cambodia, Liberia, Ruanda o Somalia.

Desde los años ochenta de este siglo se ha pasado de la aspiración a un estado en expansión creciente, que participaba directamente en la gestión económica de muchas empresas y garantizaba el bienestar del ciudadano, a una nueva visión minimalista, que ha llevado a la privatización de muchas de las actividades económicas a su cargo y a desmantelar buena parte de los servicios sociales que proporcionaba. El programa que el Banco Mundial nos propone hoy con el título de "el estado en un mundo en transformación" insiste en reducir su papel al de "sentar las bases de los fundamentos institucionales adecuados para los mercados"16

Tal vez una forma distinta de entender la génesis del estado, que implica una forma distinta de entender su naturaleza, nos ayude a fundamentar una nueva visión que valore el papel de la sociedad civil y de las asociaciones horizontales, en busca de nuevas formas de estado en que la iniciativa parta desde abajo, desde las organizaciones autónomas de los propios ciudadanos, como vemos que comienza hoy a suceder en algunos países en aquellos espacios sociales en que el estado resulta incapaz de cumplir con sus responsabilidades mínimas.

Estoy proponiendo formas de analizar el pasado 'útiles', que deberían servir para que entendiéramos mejor algunos de los grandes problemas del presente. Pero ¿acaso se puede sostener que la historia tenga una utilidad práctica? Si no la tuviera no se explicaría que los gobiernos pusieran tanto empeño en controlarla. Harvey Kaye sostiene que las clases dominantes temen la historia porque ésta es, en última instancia, el relato de la lucha de los hombres y las mujeres por la libertad y la justicia ${ }^{17}$ y Orwell ya había dicho, en su visión de un mundo totalitario, que 'quien controla el pasado controla el futuro y quien controla el presente controla el pasado'.

Esto explica la necesidad que los gobiernos sienten de controlar la historia, o sea nuestra memoria colectiva. No habrá de extrañar que Khruschev mani-

16. World development reiport 1997: The state in a changing world, Nueva York, Banco Mundial-Oxford University Press, 1997.

17. Harvey J. Kaye, Why do the ruling classes fear history?, Londres, Macmillan, 1996. 
festase en su tiempo: 'Los historiadores son gente peligrosa, capaces de volverlo todo cabeza abajo. Conviene vigilarlos' que un personaje tan pragmática como la señora Thatcher se preocupase de controlar la clase de historia que se había de enseñar en las escuelas británicas, o que la señora Aguirre esté obsesionada por su deseo de que se enseñe lo que ella llama "la verdadera historia de España", que es, naturalmente, la que legitima los valores sociales conservadores que ella defiende, como el de la prioridad de la enseñanza privada sobre la pública, por poner un solo ejemplo. O que en los Estados Unidos haya también sus "guerras de la historia", en la medida en que algunas comunidad es como las de los afroamericanos, los indios o los hispanos no aceptan la visión que se les ha estado ofreciendo.

Los usos políticos de la historia son muy diversos. Se está utilizando hoy, por ejemplo, para convencernos de que ya no hay más futuros que explorar, porque estamos en el fin de la historia. Lo cual no es verdad. Porque nunca es el fin de la historia, sino que siempre nos encontramos en el fin de una historia y en el comienza de otra o de otras cuyo curso no podemos predecir con ningún método, por refinado y científico que sea, no solo por la complejidad de la previsión, sino porque la trayectoria del porvenir dependerá de lo que entre todos queramos y sepamos hacer. Este carácter imprevisible del futuro ha sido el origen de buena parte de nuestro desánimo y de nuestro desconcierto. No debe ser así, sino que hemos de aprender a construirnos con él una esperanza que nos anime en este tiempo en que se ha generalizado una nueva serie de profecías, en esta ocasión negativas y sombrías, con el fin de recobrar la confianza en que, como ha dicho un poeta de mi tierra, "todo está por hacer y todo es posible".

Hace más de doscientos años un hombre que ha seguido siendo una referencia para todos cuantos luchan por la libertad, Tom Paine, escribió un panfleto con el titulo de Common sense, el sentido común. Este pequeño libro apareció en un año crucial: el año de la independencia de los Estados Unidos de América y el de la publicación de dos obras básicas de la cultura contemporánea: Decadencia y caída del Imperio romano de Gibbon, la obra que renovaba nuestra comprensión de la historia, y La riqueza de las naciones de Adam Smith, que fijaba las reglas de funcionamiento del desarrollo capitalista. El pequeño libro de Paine nunca ha tenido un prestigio semejante en nuestra cultura, pero no solo fue la inspiración fundamental de los revolucionarios norteamericanos, sino que es el texto que formuló por primera vez principios cargados de futuro, y todavía vigentes, como la distinción entre la sociedad civil y el estado o la defensa del derecho de las colectividades humanas a darse la forma de gobierno que desee la mayoría. Pero lo que ahora quisiera destacar de este libro es una frase concreta que deberíamos recordar siempre: 'Está en nuestras manos volver a empezar el mundo de nuevo ${ }^{\prime 18}$.

18. Thomas Paine, Common sense, Chicago, New Patriot Publications, 1976, p. 65. 
En la medida en que el historiador es quien mejor conoce el mapa de la evolución de las sociedades humanas, quien sabe la mentira de los signos indicadores que marcan una dirección única y quien recuerda los caminos que conducían a otros destinos distintos y tal vez mejores, es a él a quien toca, más que a nadie, denunciar los engaños y reanimar las esperanzas para empezar el mundo de nuevo.

Liberados de aquellas ilusiones que muchos compartimos y que hicieron de la historia, como dijo Benjamin, "el narcótico más poderoso de nuestro siglo", los historiadores debemos combatir, armados de razones, las profecías paralizadoras con que se pretende substituir a aquéllas. De ese modo contribuiremos a limpiar de maleza la encrucijada en que nos encontramos y ayudaremos a que se vean más claros los diversos caminos que se nos abren por delante y a que entre todos elijamos los mejores. 